\title{
Tubercular cold abscess at an unusual site mimicking a pyogenic abscess
}

\author{
S Abqari, ${ }^{1} \mathrm{MD}$; A Anjum, ${ }^{1} \mathrm{DCH}, \mathrm{MD} ; \mathrm{D}$ I Khan, ${ }^{2} \mathrm{MD} ; \mathrm{T}$ Nawab, ${ }^{1} \mathrm{MD} ; \mathrm{M}$ Sardha,${ }^{3} \mathrm{MD}$ \\ ${ }^{1}$ Faculty of Medicine, Jawaharlal Nehru Medical College, Aligarh Muslim University, Aligarh, Uttar Pradesh, India \\ ${ }^{2}$ University Health Service, Aligarh Muslim University, Aligarh, Uttar Pradesh, India \\ ${ }_{3}^{3}$ International Medical School, Management \& Science University, Shah Alam, Malaysia
}

Corresponding author: A Anjum (arshadanjum@yahoo.com)

\begin{abstract}
Tuberculosis affects much of the world's population, and $1-5 \%$ of all cases are musculoskeletal. Tuberculosis of the soft tissues secondary to underlying bone involvement is not uncommon, but selective tissue involvement without bony abnormality is rare. We present a case in which two tubercular abscesses presented at an unusual site with no underlying bony involvement, simulating a pyogenic abscess.
\end{abstract}

S Afr J CH 2013;7(2):77-78. DOI:10.7196/SAJCH.578

Tuberculosis affects a significant percentage of the world's population, and musculoskeletal tuberculosis constitutes $1-5 \%$ of all cases. ${ }^{[1]}$ Tuberculosis of the soft tissues, in the form of conditions such as tubercular bursitis, tubercular synovitis and tubercular spondylitis secondary to underlying bone involvement, is not uncommon..$^{[2-3]}$ Selective tissue involvement without bony abnormality, however, is rare. We hereby present a case in which two tubercular abscesses presented at an unusual site with no underlying bony involvement, simulating a pyogenic abscess.

\section{Case report}

A 2-year-old boy presented with complaints of fever, cough and progressively increasing swellings on both lower limbs for the past 1.5 months. He also had decreased appetite and poor weight gain. There was no history of contact with a case of tuberculosis. On examination two discrete swellings were noted, one measuring $3 \times 4 \mathrm{~cm}$ and situated on the dorsal aspect of the right foot just below the lateral malleolus (Fig. 1) and the other, measuring $5 \times 6 \mathrm{~cm}$, on the left leg just above left lateral malleolus, with no evidence of inflammation (Fig. 2). The swellings were non-tender, mobile, superficial and without any discharging sinus.

A full blood count showed lymphocytosis, the Mantoux test was strongly positive with cross-sectional (horizontal) induration of $16 \mathrm{~mm}$, the chest radiograph showed some hilar prominence, and fine-needle aspiration cytology (FNAC) showed acid-fast bacilli on Ziehl-Neelsen staining (Fig. 3). Radiographs showed no evidence of underlying osteomyelitis.

A diagnosis of tubercular abscess was made and the child was placed in category III of the Revised National Tuberculosis Programme and started on antituberculosis treatment in the form of $2 \mathrm{HRZ}, 4 \mathrm{HR}$ (2 months of isoniazid $(\mathrm{H})$, rifampicin $(\mathrm{R})$ and pyrazinamide $(\mathrm{Z})$, followed by 4 months of $\mathrm{H}$ and $\mathrm{R})$. He responded to the treatment. The size of the swellings reduced markedly, and he had gained weight when seen on his first follow-up visit. Subsequently he was lost to follow-up.

\section{Discussion}

Extrapulmonary tuberculosis accounts for up to one-third of all cases. Children have a higher predisposition to the development of extrapulmonary tuberculosis. ${ }^{[4]}$ Tuberculosis can involve the soft tissues by extension from bone, synovial lining of joints or tendon sheaths; by direct inoculation; and, rarely, by haematogenous dissemination. ${ }^{[5]}$ However, selective primary softtissue involvement without osseous involvement is rare. It probably occurs via haematogenous spread from an occult primary focus elsewhere. Magnetic resonance imaging (MRI), especially with

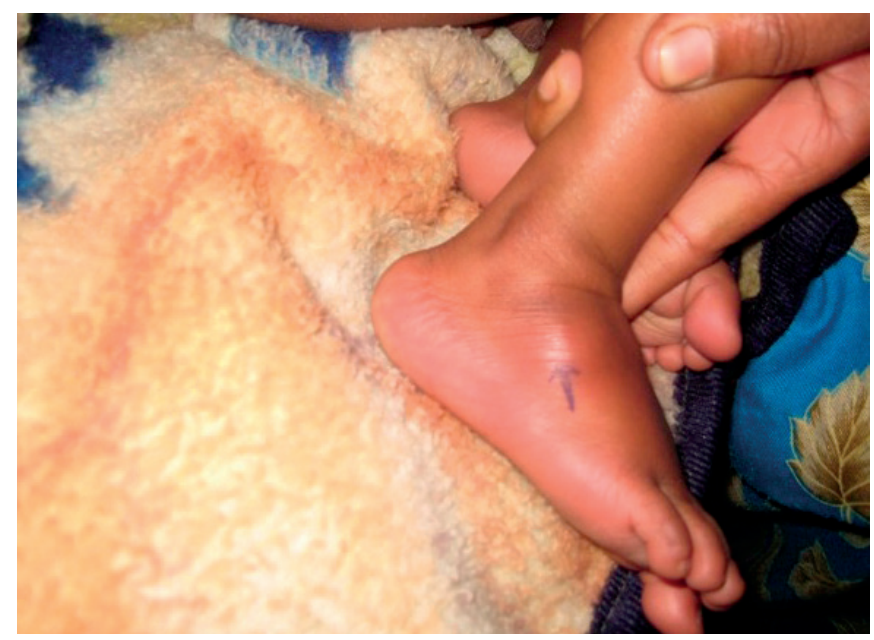

Fig. 1. A 2-year-old boy with a swelling measuring $3 \times 4 \mathrm{~cm}$ on the dorsal aspect of the right foot just below the lateral malleolus.

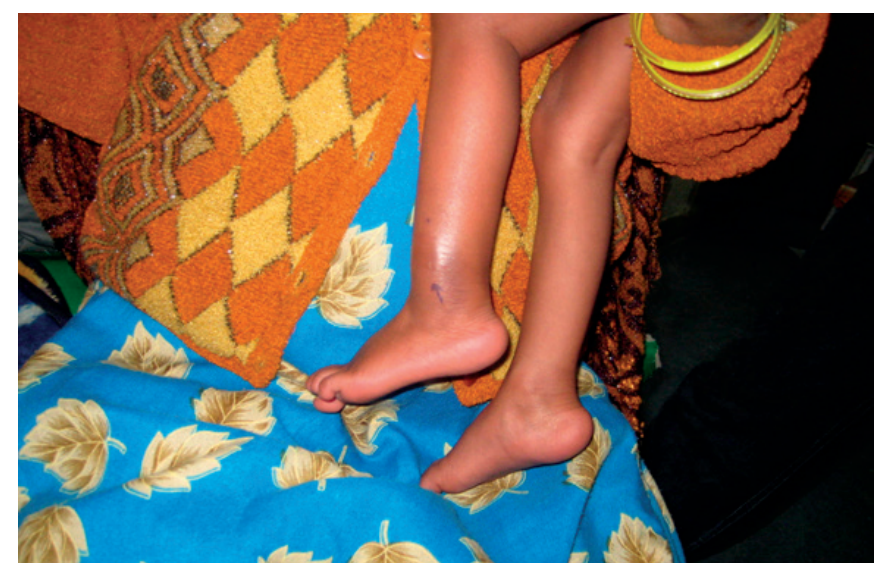

Fig. 2. The same patient, with a swelling measuring $5 \times 6 \mathrm{~cm}$ on the left leg just above the left lateral malleolus. 


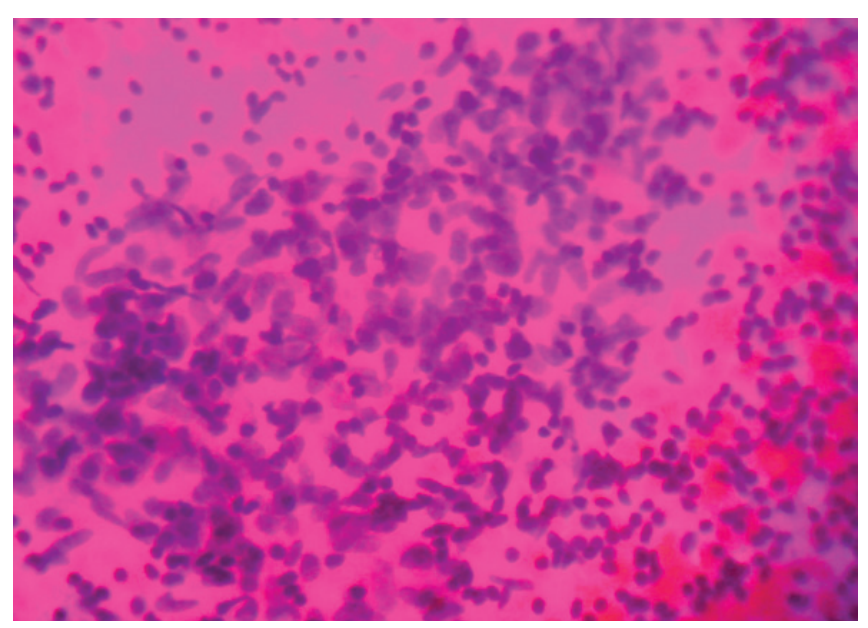

Fig. 3. Fine-needle aspiration cytology showing acid-fast bacilli on ZiehlNeelsen staining with smears showing clusters of epithelioid cells along with lymphoid cell population in a haemorrhagic background (H\&E×100).

gadolinium enhancement, is very helpful in the diagnosis of softtissue abscesses, but tissue diagnosis is confirmatory. Tuberculous polymyositis has characteristic features of a well-demarcated abscess with rim enhancement on MRI. ${ }^{[6]}$ However, needle aspiration and examination is usually sufficient. Our patient's family could not afford MRI, but FNAC was suggestive of tuberculosis without clearly identifying the tissue localisation. Tuberculosis should be considered in the differential diagnosis of any unexplained soft-tissue swelling in people born in tuberculosis-endemic areas.

Consent. Written informed consent was obtained from the patient's guardian for publication of this case report and the accompanying images. A copy of the written consent is available from the authors.

Author contributions. SA and AA collected the data, and analysed and interpreted the literature and put together the case report, DIK was involved in collecting pictures and reviewing articles, SA, AA, TN and MS drafted and proof-read the manuscript, and SA, DIK and TN gave final approval of the version to be published. All authors read and approved the final manuscript.

\section{References}

1. Weir MR, Thornton GF. Extrapulmonary tuberculosis: Experience of a community hospital and review of the literature. Am J Med 1985;79(4):467478. [http://dx.doi.org/10.1016/0002-9343 (85)90034-8]

2. Abdelwahab IF, Kenan S, Hermann G, et al. Tuberculous peroneal tenosynovitis: A case report. J Bone Joint Surg Am 1993;75(11):1687-1690.

3. Goldberg I, Avidor I. Isolated tuberculous tenosynovitis of the achilles tendon: A case report. Clin Orthop Relat Res 1985;194:185-188. [http://dx.doi. org/10.1097/00003086-198504000-00027]

4. Tappeiner G, Wolff K. Tuberculosis and other mycobacterial infections. In: Fitzpatrick TB, Freedberg IM, Eisen AZ, Wolff K, eds. Dermatology in General Medicine. New York: McGraw-Hill, 1999:2274-2292.

5. Derkash RS, Makley JT. Isolated tuberculosis of the triceps muscle: Case report. J Bone Joint Surg Am 1979;61(6A):948.

6. Kim JY, Park YH, Choi KH, et al. MRI of tuberculous pyomyositis. J Comput Assist Tomogr 1999;23(3):454-457. [http://dx.doi.org/10.1097/00004728 199905000-00023] 